\title{
REINTERPRETANDO LA RESPONSABILIDAD DEL PROPIETARIO ANTE DAÑO AMBIENTAL INDIRECTO DERIVADO DE ACTIVIDADES RIESGOSAS DEL USUFRUCTUARIO Y DEL SUPERFICIARIO ${ }^{1}$
}

\author{
LAND USE ARRANGEMENTS AND \\ ENVIRONMENTAL DAMAGES: A \\ REASSESSMENT OF THE PROPERTY \\ OWNERS LIABILITY
}

HARAVÍ ELOÍSA RUIZ

GUILLERMO GAPEL REDCOZUB

UNIVERSIDAD NACIONAL DEL NORDESTE

ARGENTINA.

“...Se trata pues de considerar el derecho de una manera nueva y fecunda: como un elemento vivo y continuamente progresivo de la vida social; y de estudiarlo en el ejercicio mismo de esta vida social. Esto es verdaderamente conocer el derecho, conocer su genio, su misión, su rol. Es así como las leyes mismas nos mandan comprenderlo, porque es el alma, la vida, el espíritu de las leyes. Saber, pues, leyes, no es saber derecho; porque las leyes no son más que la imagen imperfecta y frecuentemente desleal del derecho que vive en la armonía viva del organismo social...”. Juan Bautista Alberdi 


\title{
RESUMEN
}

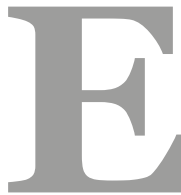

El Código Civil y Comercial de la Nación contiene diversos instrumentos jurídicos que permiten desdoblar la titularidad de un recurso productivo del derecho de uso y goce sobre el mismo, como los derechos reales de usufructo y superficie. Si al explotar el recurso el usufructuario o superficiario lleva a cabo actividades riesgosas que ocasionan daño ambiental indirecto, el sistema de responsabilidad civil se debe integrar con normativa de orden ambiental. En este esquema corresponde reinterpretar la norma aplicable y concluir que el propietario puede ser considerado responsable por tales daños cuando se apropie de parte de la mayor rentabilidad generada por dicha actividad.

Palabras clave: responsabilidad civil; daño ambiental; actividades riesgosas; usufructo; superficie.

\begin{abstract}
The Argentine Civil and Commercial Code includes a set of land use arrangements that allow to divide ownership of an asset from the right to use it. Among these arrangements we can find the rights named "usufructo" and "superficie". If the operator that took control of the asset by choosing any of these legal tools performs dangerous activities causing damages to third parties, we hold that the owner could also be considered responsible whenever he profits from the extraordinary gains produced by the risky activity.
\end{abstract}

Keywords: owner liability; environmental damage, dangerous activities; land use arrangements.

\section{INTRODUCCIÓN}

El Código Civil y Comercial de la Nación (CCCN) contiene diversos instrumentos que permiten dividir o separar la titularidad de un recurso productivo del derecho de uso y goce sobre el mismo. Este desdoblamiento puede producirse mediante la celebración de contratos que constituyan derechos personales, los que comprenden desde la tradicional locación hasta el

\footnotetext{
${ }^{1}$ Este artículo utilizó como base los estudios realizados para la ponencia "Responsabilidad del nudo propietario por daño ambiental indirecto derivado de actividades riesgosas del usufructuario", de los mismos autores, presentada en la Comisión № 4 de las XXV Jornadas Nacionales de Derecho Civil, celebradas en la ciudad de Bahía Blanca en octubre de 2015.
} 
moderno leasing, o bien puede originarse en contratos que den nacimiento a derechos reales, como el usufructo o la superficie.

Las razones para que un sujeto adopte un esquema productivo de este tipo pueden ser variadas: le puede resultar financieramente más conveniente no inmovilizar capitales en la compra de un inmueble, carecer de fondos suficientes para adquirir la cosa, su contratante puede no tener la voluntad de desprenderse de la propiedad del activo, o bien puede suceder que le esté prohibido acceder a la titularidad del recurso, como sucede en ciertos supuestos con los extranjeros y los inmuebles rurales merced a la denominada Ley de Tierras Rurales (Ley $\mathrm{N}^{\circ}$ 26.737), entre otros posibles factores.

Cuando se va a llevar adelante un emprendimiento productivo bajo alguna modalidad de desdoblamiento por un plazo considerablemente prolongado, resulta habitual que el emprendedor tenga preferencia por la celebración de contratos que le otorguen derechos reales antes que derechos personales, en razón de que aquellos generalmente permiten la asignación del recurso durante más años, otorgan mayor seguridad en la posesión del activo, y en algunos casos, hasta podrían ser utilizados para constituir garantías reales.

Dos de los derechos reales diseñados por el legislador para dar soporte jurídico a esta clase de emprendimientos son el usufructo y la superficie, cuyas notas sobresalientes serán tratadas más adelante. Mientras que el primero se conoce de larga data, el último fue incorporado al catálogo de derechos reales en una versión acotada en el año 2001 mediante la Ley de Superficie Forestal $\mathrm{N}^{\circ}$ 25.509, y ampliado con la reciente sanción del CCCN. Aunque ajeno a las tradiciones de nuestro país, lo que posiblemente se deba a que estuvo prohibido por más de 130 años, un sector de la doctrina alberga esperanzas de que resulte finalmente útil y de que su empleo se generalice. ${ }^{2}$

Entre las ventajas propiciadas por la organización productiva a través del derecho real de superficie, se alega que:

“...el mencionado nuevo derecho real permite, entre otras cosas: a) Posibilitar que tierras improductivas por la falta de capital de trabajo de sus titulares entren al circuito virtuoso de la producción sin tener que desprenderse de sus propiedades que, tal vez por generaciones, se encuentran en el acervo familiar; $b$ ) Facilitar a las provincias la "puesta en producción" de tierras fiscales ociosas, cediendo el uso del "espacio o vuelo de las mismas", sin descapitalizarse por su venta y beneficiándose con las mejoras y el efecto multiplicador de la actividad

\footnotetext{
2"No se crea que el éxito de la superficie es automático. Diez Picazo y Gullón recuerdan que en derecho español la superficie sigue sin vitalidad entre particulares. En el criterio de estos autores no se conseguirá el despegue de la misma del texto de las leyes a la práctica hasta que no cambie la mentalidad social que no concibe que la propiedad de una vivienda no lleve consigo la propiedad del suelo en el que está edificada, ni que pueda obtenerse una renta simplemente de él (la contraprestación del superficiario) [...] No basta, entonces, con la sola recepción legislativa, que aplaudimos, se necesitará -además del cambio sociológico del que hablan los maestros españoles- un legislador atento a solucionar de inmediato los problemas interpretativos que puedan darse en la práctica, una judicatura que le otorgue viabilidad con interpretaciones que favorezcan su vigencia y sobre todo que la nueva figura sea acompañada por una normativa impositiva y administrativa adecuada." (Cossari y Luverá, 2002, p.7).
} 
productiva en las economías locales; c) Dar lugar a que los propietarios endeudados y con sus inmuebles gravados, tengan un flujo de fondos ciertos, para permitirles "limpiar" sus pasivos, evitando costosas ejecuciones, tanto desde el punto de vista social como político; d) Permitir que los hoy propietarios de las tierras de sus ancestros, se capitalicen a través de las mejoras y de las importantes rentas generadas (Gómez de la Lastra, 2013, p.1).

En sustento del optimismo de los defensores de esta joven figura, puede afirmarse que en la región Nordeste del país el derecho de superficie forestal ha ganado cierto espacio como una de las alternativas jurídicas en torno a las cuales se organizaron las inversiones forestales de la última década, favorecidas por los incentivos económicos promovidas por la Ley de Bosques $\mathrm{N}^{\circ} 25.080 .^{3}$

Aunque los datos no son homogéneos ni completos, lo que genera ciertas dificultades y limitaciones en el estudio del fenómeno, las estadísticas oficiales del Ministerio de Agroindustria señalan que la Provincia de Corrientes cuenta con 426.0oo has forestadas (al año 2015), la de Misiones con 352.000 has (al año 2009), y la de Entre Ríos con 154.0oo has (al año 2014), lo que hace un total de 932.000 has. Esta cantidad representa, en términos aproximados, el $80 \%$ de las plantaciones forestales del país ${ }^{4}$, aclarando que la información disponible no permite discernir entre los diversos regímenes jurídicos bajo los cuales se explotan estas superficies (dominio perfecto, arrendamiento, derecho real de superficie, entre otras alternativas).

Mientras la forestación se consolida como una actividad económica de relevancia para el país y, en especial, para la región mesopotámica, diversos autores advierten sobre las consecuencias negativas que ella puede ocasionar, tanto al ambiente como a las personas. Señalan como posibles perjuicios:

a) La disminución de las fuentes de agua. Overbeek, Kröger y Gerber (2012)

afirman que:

“... una de las cuestiones más controvertidas entre la población y las compañías de PIA [Plantaciones Industriales de Árboles] se refiere al agotamiento de los ríos, arroyos y pozos locales. En todos los relatos documentados sobre las reacciones de las comunidades frente a las PIA, la gente se queja, sin excepción, de que sus fuentes de agua han disminuido o se han secado" (p.31).

\footnotetext{
${ }^{3}$ Señala Alterini (2003) que el régimen de la ley 25080 importa centralmente un tratamiento fiscal especial y de apoyo económico no reintegrable para quienes realicen efectivas inversiones en la actividad promovida, consistente en la implantación, mantenimiento, protección y cosecha de bosques, incluyendo la industrialización de la madera, cuando el conjunto de todas ellas formen parte de un emprendimiento forestal o forestoindustrial integrado, mas esta norma, resalta, no tiene incidencia decisiva en el ordenamiento estructural del nuevo derecho real.

${ }^{4}$ Fuente: Ministerio de Agroindustria de la Nación. Disponible en: http://ambiente.gob.ar/?idseccion=42
} 
En igual sentido, Carrere (2004) explica que:

“...el volumen de agua disponible tiende a disminuir luego de la instalación de estas plantaciones. En realidades tan diversas como el sur de Chile, el estado de Espírito Santo en Brasil, Sudáfrica o Tailandia, se constata que el régimen hídrico sufre cambios negativos importantes como resultado de la plantación de grandes áreas de pinos y eucaliptos de rápido crecimiento. Ello se debe a varios factores, pero el principal es el elevado consumo de agua de estas especies (p.7).

b) La contaminación de los cursos de agua vecinos. Overbeek et al. (2012) aseguran que, además, "las PIA también afectan de otra forma el agua local: los arroyos y ríos se contaminan con los productos químicos empleados [...], y esto incide sobre la pesca, la disponibilidad de agua potable" (p. 32).

c) Adicionalmente, la forestación puede generar la pérdida de riqueza de los suelos. Resalta Overbeek et al (2012) que:

Los efectos negativos sobre el suelo son otro motivo frecuente de quejas. Como se trata de cultivos de crecimiento rápido, de cosecha rotativa, las PIA eliminan constantemente los nutrientes del suelo. Como resultado, deben ser aplicados fertilizantes químicos que, a su vez, contaminan el suelo y el agua. La erosión es un problema corriente, especialmente en terrenos accidentados. En el caso de algunas praderas, el impacto sobre los suelos puede ser irreversible y hacer peligrar la agricultura y otras actividades futuras. Carlos Céspedes Payret, investigador de la Facultad Uruguaya de Ciencias, demostró que las plantaciones de eucaliptos tienen efectos negativos sobre las praderas: provocan una considerable pérdida de materia orgánica, aumentan la acidez, y alteran otras propiedades fisicoquímicas del suelo (Céspedes Payret citado en Overbeek et al. 2012, p. 33).

d) También se registran estudios que refieren la existencia de significativas pérdidas de biodiversidad en las zonas de desarrollo plantaciones industriales (FAO, 2002).

Este auge forestal, con sus riesgos ambientales aparejados, presenta una interesante oportunidad para reflexionar acerca de lo que ocurre cuando se entrecruzan el fenómeno del desdoblamiento productivo organizado a través de la constitución de derechos reales y el régimen de responsabilidad por actividades riesgosas ante daños a terceros o sus bienes.

¿Qué sucede cuando se producen daños a terceros como consecuencia de actividades riesgosas generadas en el marco de emprendimientos productivos organizados por medio de estos derechos reales? ¿Quién debe indemnizar a los afectados? ¿Es posible que el "nudo" propietario tenga algún tipo de responsabilidad por la actividad riesgosa desarrollada por el 
superficiario o usufructuario que efectivamente explota el inmueble?

Con independencia de las sanciones que le correspondan a quienes realicen o intervengan directamente en las actividades que resulten contaminantes, el presente trabajo se enfoca en analizar la eventual responsabilidad civil de los propietarios ante daños ambientales a terceros ocasionados por los superficiarios o usufructuarios a quienes han cedido la explotación del recurso ${ }^{5}$, en función del bloque normativo compuesto por la Constitución Nacional, las leyes especiales y el Código Civil y Comercial de la Nación (CCCN).

Iniciaremos esta tarea revisando las notas sobresalientes de los derechos reales de superficie y usufructo, luego distinguiremos las distintas clases de daños ambientales, continuaremos con la descripción de las posibles interpretaciones del esquema vigente de responsabilidad ambiental por daños a terceros derivados de actividades riesgosas, entre las que incluiremos una propuesta interpretativa del art. $1758 \mathrm{CCCN}$ que incorpora la figura del propietario "aprovechador", para avanzar posteriormente sobre los fundamentos por los cuales entendemos que esta última postura se adapta mejor al referido bloque de legalidad. Finalmente precisaremos cuál es la situación en la que se encuentra el propietario "aprovechador" frente a daños ambientales indirectos ocasionados por el superficiario o usufructuario.

\section{DERECHOS REALES DE SUPERFICIE Y USUFRUCTO. SUS CARACTERÍSTICAS SOBRESALIENTES}

El Código Civil y Comercial de la Nación (CCCN) instaura una versión amplia del derecho real de superficie, el que había sido creado originariamente mediante la ley No 25.509 del año 2001.

La versión originaria otorgaba a su titular el uso, goce y disposición jurídica de la superficie de un inmueble ajeno, con la facultad de realizar forestación o silvicultura y hacer propio lo plantado o adquirir la propiedad de plantaciones ya existentes (art. 2 Ley 25.509). En su redacción actual, el objeto del derecho se expande y trasciende los límites de la forestación, incorporando específicamente a su contenido la facultad de edificar y la de hacer propia una construcción ya existente, con independencia de la propiedad sobre el inmueble en el que se sitúa o se situará la edificación (art. $2114 \mathrm{CCCN})^{6}$.

La doctrina explica que este es:

\footnotetext{
${ }^{5}$ Se dejan fuera del objeto del trabajo a los daños generados directamente al ambiente por parte del superficiario, en razón de que estos daños se encuentran regulados por un bloque de legalidad distinto, como se explica más adelante.

${ }^{6}$ Artículo 2114.- Concepto. El derecho de superficie es un derecho real temporario, que se constituye sobre un inmueble ajeno, que otorga a su titular la facultad de uso, goce y disposición material y jurídica del derecho de plantar, forestar o construir, o sobre lo plantado, forestado o construido en el terreno, el vuelo o el subsuelo, según las modalidades de su ejercicio y plazo de duración establecidos en el título suficiente para su constitución y dentro de lo previsto en este Título y las leyes especiales.
} 
“...un derecho real inmobiliario que se ejerce separadamente del derecho del dueño del terreno. La obra sobre suelo del inmueble o debajo de él no es atraída por la propiedad del aquél. La superficie constituye una carga real con relación al dueño de la cosa (art.1888), quien tendrá un dominio imperfecto o desmembrado (art. 1964), pudiéndoselo calificar de "nuda propiedad" (Mariani de Vidal y Abella, 2016, p.3).

Las facultades de uso, goce y disposición con las que cuenta el superficiario pueden adoptar dos modalidades: una, consiste en el derecho de realizar construcciones, plantaciones o forestaciones sobre el terreno, el espacio aéreo y el subsuelo del inmueble ajeno, haciendo propio lo plantado, forestado o construido; la otra, cuando el derecho se concede sobre sobre plantaciones, forestaciones o construcciones ya existentes, atribuyendo al superficiario su propiedad (art. 2115 CCCN).

Se permite la constitución del derecho de superficie sobre todo el inmueble o sobre una parte determinada, con proyección en el espacio aéreo o en el subsuelo, o sobre construcciones ya existentes aun dentro del régimen de propiedad horizontal (art. 2116), por hasta un plazo máximo de setenta años cuando se trata de construcciones y de cincuenta años para las forestaciones y plantaciones, ambos contados desde la adquisición del derecho (art. 2117).

El Código sólo prevé expresamente su conformación por contrato (oneroso o gratuito), por parte de los titulares de los derechos reales de dominio, condominio y propiedad horizontal, y puede ser transmitido por actos entre vivos o por causa de muerte. No se admite la adquisición por usucapión, aunque la prescripción breve procede a los efectos del saneamiento del justo título (art. 2119). ${ }^{7}$

En cuanto a las facultades del superficiario se incluyen las de constituir derechos reales de garantía sobre el derecho de construir, plantar o forestar o sobre la propiedad superficiaria (limitados siempre al plazo de duración de su derecho), y la de afectar la construcción al régimen de la propiedad horizontal, autorizándosele a transmitir y gravar como inmuebles independientes las viviendas, locales u otras unidades privativas, durante el plazo del derecho de superficie, salvo pacto en contrario (art. 2120).

Con relación a las facultades del propietario, la norma resulta un tanto lacónica, limitándose a sostener que éste conserva la disposición material y jurídica que corresponde a su derecho, debiendo ejercerla sin turbar el derecho del superficiario (art. 2120). Kiper (2015) sostiene que esta fórmula es correcta dado que trata de proteger al superficiario sin limitar innecesariamente al dueño.

\footnotetext{
${ }_{7}^{7}$ Sobre la posibilidad de constituir el derecho de superficie por disposición testamentaria (no mencionada en el art. 2119), Mariani y Abella sostienen que "al respecto la doctrina, ocupándose de la ley 25.509 de Superficie Forestal, no era uniforme. La tesis negativa se sustentaba en el carácter de orden público de las normas regulatorias de la adquisición de los derechos reales, que no mencionaban al testamento como fuente de este derecho; para otros carecía de sentido privar al testador de la facultad de establecerlo, en tanto no lesionara la legítima. Las disidencias posiblemente subsistirán bajo el nuevo Código" (2016, p.8).
} 
Mariani y Abella (2016, p.11), remarcan que "el superficiario puede haber asumido en el contrato de creación distintas obligaciones - relativas, por ejemplo, a la clase de construcciones a ejecutar, especies a plantar, modo de explotación, etc. - que fijarán los contornos de su derecho”y más importante aún, subrayan que el uso que hace el superficiario del inmueble debe ajustarse a su destino, sin desnaturalizarlo ni degradarlo, aunque no brindan referencias explícitas sobre el origen de estas obligaciones.

Finalmente, la regulación establece cuáles son las causales de extinción de la figura y sus efectos, que aquí omitiremos en razón de que no son relevantes para el trabajo, destacando, eso sí, que se instituye un sistema de protección a los terceros que contraten con el superficiario para el caso de que el derecho real se extinga antes del cumplimiento del plazo legal o convencional (art. 2125).

Respecto del derecho real de Usufructo, el Código Civil disponía en el art. 2812 sus cuatro formas posibles de constitución (contrato oneroso o gratuito, actos de última voluntad, disposición legal y prescripción). En cambio, en el Libro IV Título VIII del CCCN, lugar donde se encuentra regulado el usufructo actualmente, no se previó normativa específica sobre formas de constitución. Corresponde entonces recurrir a las disposiciones generales sobre derechos reales para concluir que, vía aplicación de los principios comunes, la creación del usufructo requiere de título suficiente (art. $1892 \mathrm{CCCN}$ ). Esto equivale a decir que el derecho real de usufructo, también bajo las nuevas disposiciones, nace a partir de un contrato de usufructo con las formalidades de ley (sin perjuicio de la existencia de otras formas constitutivas).

El contenido del contrato se encuentra desarrollado en el Libro IV Título VIII, comprendiendo: objeto del derecho, designación de beneficiario, modalidad, inventario o detalle del estado del objeto (elemento que en ciertos casos es optativo), y una garantía de carácter opcional.

El CCCN agrega a continuación las características propias de la estructura o tipología legal del usufructo, donde se establecen derechos y obligaciones de las partes. Junto a esta serie de normas inmodificables el contrato contendrá otro conjunto de derechos y obligaciones o modalidades que son las que las partes pueden acordar (ej. gratuidad o precio y forma de pago, condición, plazo, etc.), hallando aquí los particulares un espacio de autonomía para amoldar la naciente relación jurídica a sus intereses.

Dentro de la estructura legal del derecho real, la obligación del nudo propietario se circunscribe a no turbar el uso y goce del usufructuario bajo pena de que éste último reclame una disminución del precio acordado según el contrato de usufructo (art. 2151).

Sobre la cuestión de las obligaciones del usufructuario, cabe destacar que la principal consiste en la necesidad de que ajuste el uso y goce de la cosa a su destino, el que se determina "por la convención, por la naturaleza de la cosa o por el uso al cual estaba afectada de hecho" (art. 2145).

De esta apretada síntesis se puede colegir que los parámetros fijados por las estructuras legales se circunscriben a regular estrictamente la relación entre propietario, por una parte, y superficiario u usufructuario, por la otra, y en todo caso, la situación de los terceros que con- 
traten con el superficiario, mas no brindan referencias sobre la eventual responsabilidad que el primero puede tener en caso de que el ocupante de la cosa dañe a un tercero.

Esta decisión legislativa, bastante común por cierto, difiere sin embargo de la tomada en otros contratos que también importan transmisión de relaciones de poder sobre cosas, donde se fijan pautas específicas de responsabilidad por daños frente a terceros como sucede en los casos del seguro del fiduciario (art. 1685) y del tomador del leasing (art. 1243). ${ }^{8}$

En consecuencia, para resolver la cuestión particular de la posible existencia de responsabilidad del propietario en caso de que la conducta del superficiario o usufructuario ocasione daño ambiental indirecto debemos remitirnos al sistema general de responsabilidad y, en particular, a la normativa sobre responsabilidad por daño ambiental. A continuación, nos detendremos en estas cuestiones, previo paso necesario por las categorías del daño ambiental.

\section{DAÑO AMBIENTAL. CONCEPTO Y CLASES}

En materia ambiental tanto la doctrina como la jurisprudencia distinguen dos tipos de daños: el daño ecológico o directo y el daño de rebote o indirecto.

El primero, denominado también daño ambiental stricto sensu, impacta directamente sobre la entidad ambiente y está constituido por cualquier tipo de degradación física, química o biológica relevante que lo afecte negativamente. Comprende el deterioro del entorno o hábitat, el menoscabo al paisaje, y el perjuicio al patrimonio cultural. ${ }^{9}$ Di Paola (2010) señala que el daño ambiental per se altera o destruye parcial o totalmente los ecosistemas y la calidad de vida de los seres vivos que lo componen. Se trata de una protección inmediata sobre el ambiente, aunque no se ocasione daño a persona alguna.

El segundo, el daño de rebote o indirecto, es el perjuicio al patrimonio o la salud de una o varias personas determinadas que se produce a través de disfuncionalidades ambientales (López Alfonsín, 2012), en otras palabras, un daño a la persona y sus bienes por alteración del ambiente (Walsh y Preuss, citados en Cafferatta, 2008), concepto que entiende justamente al ambiente como un medio para producir un menoscabo a las personas o sus bienes (Di Paola, 2012).

Lo habitual es que los daños directos e indirectos se presenten de manera simultánea, lo que lleva a la doctrina a destacar el rasgo de bipolaridad o de doble cara como característico de la fisonomía del daño ambiental (Caferatta, 2008).

Lo anterior no obsta a que ambos sea nítidamente diferenciables según el bien jurídico

\footnotetext{
8 El CCCN dispone que la responsabilidad objetiva emergente del artículo 1757 (hechos y actividades riesgosas) recae exclusivamente sobre el tomador o guardián de las cosas dadas en leasing (art. 1243). También establece que el fiduciario es responsable en los términos de los artículos 1757 y concordantes cuando no haya contratado seguro de responsabilidad civil o cuando éste resulte irrazonable en la cobertura de riesgos o montos (art. 1685).

${ }^{9}$ La Ley General del Ambiente (LGA) № 25.675 define el daño ambiental propiamente dicho en su artículo 27 como “[...] toda alteración relevante que modifique negativamente el ambiente, sus recursos, el equilibrio de los ecosistemas, o los bienes o valores colectivos".
} 
afectado en cada caso: en el daño ambiental directo lo es el ambiente como bien de carácter colectivo, mientras que en el indirecto o de rebote lo son los derechos individuales de las personas cuya salud o patrimonio ha padecido un menoscabo a raíz del evento dañino al ambiente.

A partir de la clasificación expuesta también se determina cuáles son las normas aplicables, la legitimación activa, las facultades del juez, la naturaleza de la reparación, y si correspondiera, el destino de la indemnización pecuniaria.

En el caso del daño ambiental directo se deben aplicar el art. 41 de la Constitución Nacional, los Pactos Internacionales incorporados, el régimen de responsabilidad previsto en los arts. 27 a 33 de la Ley General del Ambiente (LGA), el bloque de normas federales conocidas como "Presupuestos Mínimos Ambientales" ${ }^{10}$ y las normas provinciales y municipales de la jurisdicción de su acaecimiento o posible concurrencia. A su vez, las normas aplicables para el caso de los daños de rebote, son las de responsabilidad del derecho civil (Di Paola, 2012), que comúnmente se conocen con la denominación de "daños personales, patrimoniales o económicos” (López Alfonsín, 2012, p.247). En el CCCN se sitúan en los arts. 1749 y siguientes, para los casos de responsabilidad directa, y en los arts. 1757 y siguientes, para los de responsabilidad derivada de actividades riesgosas. Cabe resaltar, en virtud de que en este caso particular el daño se genera a través del ambiente, que la aplicación de las normas civiles señaladas debe realizarse siempre en sintonía con lo dispuesto en el art. 41 de la CN y la LGA.

En cuanto a la legitimación activa, en materia de daño ambiental de incidencia colectiva es aplicable el art. 30 de la LGA y $43 \mathrm{CN}$, mientras que en el daño ambiental individual, rigen los principios ordinarios del Código Civil y Comercial, según el menoscabo sea patrimonial (arts. 1772 y 113 CCCN) o moral (art. 1741 CCCN) (Pizarro, 2015).

Por último, la responsabilidad derivada del daño ambiental colectivo posee prioritariamente una función recompositiva ${ }^{11}$ y sólo de manera accesoria o subsidiaria procede la indemnización pecuniaria, la cual se destina al Fondo de Compensación Ambiental que crea la LGA (art. 34). Tratándose de daño ambiental individual, la naturaleza de la responsabilidad es principalmente resarcitoria y el monto indemnizatorio se destina a cada damnificado, en la medida del daño efectivamente sufrido. Se destaca que respecto a la función preventiva de la responsabilidad ambos sistemas se han asimilado notablemente a partir de la sanción del nuevo CCCN (arts. 1708, 1710 a $1713 \mathrm{CCCN}$ ). ${ }^{12}$

\footnotetext{
${ }^{10}$ Compuesto por las Leyes Nacionales № 24.051 de "Residuos Peligrosos", № 25.612 de "Gestión Integral de Residuos Industriales y de Actividades de Servicios,", № 25.670 de "Gestión y Eliminación de PCB", №25.688 de "Gestión Ambiental de Aguas", № 25.831 de "Libre acceso a la Información Pública", № 25.916 de "Presupuestos Mínimos para la Gestión de Residuos Domiciliarios", № 26.331 de "Protección Ambiental de Bosques Nativos", № 26.562 de "Actividades de quema en todo el Territorio Nacional", y № 26.639 de "Preservación de los Glaciares y del Ambiente Periglacial".

${ }^{11}$ Cabe destacar que la función prioritaria de recomponer el daño ambiental colectivo tiene origen directo y expreso en la CN: "EI daño ambiental generará prioritariamente la obligación de recomponer, según lo establezca la ley." (art. 41 1er. párrafo ultima parte). ${ }^{12}$ La reforma del año 1994 de la CN y la LGA del año 2002 reconocen los principios Preventivo y Precautorio en materia ambiental de incidencia colectiva. En cambio, la función preventiva del derecho de daños es más reciente en el ámbito civil, siendo consagrada legislativamente con la sanción del CCCN a finales del año 2014.
} 


\section{FUENTES DE LA RESPONSABILIDAD POR DAÑO AMBIENTAL INDIRECTO DERIVADO DE ACTIVIDADES RIESGOSAS}

$\mathrm{Al}$ analizar el art. $1757^{13} \mathrm{CCCN}$ explica Galdós (2016) que:

“...la actividad riesgosa o peligrosa se constituye con una conjunción de acciones, conductas, operaciones o trabajos desarrollados por una persona, empresa $u$ organización económica, que puede estar vinculada causalmente con cosas o con conjuntos de cosas - aunque esto no es excluyente-, y de las que se desprende riesgo (la inminencia de daño) o peligro (la situación que puede generar daño) [...] La jurisprudencia sostuvo muy claramente que "la actividad será 'riesgosa por su naturaleza' cuando intrínseca y naturalmente, cualesquiera sean las circunstancias en las que se efectúe, la actividad conlleve un peligro inmanente ( $v$. gr. explotación de energía nuclear). Las actividades peligrosas 'por las circunstancias de su realización' son aquellas en la que no obstante no revestir un peligro regular o constante las modalidades de tiempo, modo y lugar la tornan peligrosa. Por ejemplo, el trabajo en la construcción o en obra" (TS Córdoba, Sala Civil y Comercial, “Arias de Fernández, Blanca c/ Tagle (h) y Cía. SA”, del 6/9/2004,). La actividad es riesgosa por los medios empleados cuando normalmente es inocua, pero adquiere peligrosidad porque una persona hace uso de mecanismos, instrumentos, aparatos o sustancias que son peligrosas por la velocidad que desarrollan, por su naturaleza explosiva o inflamable, por la energía que contienen, por el lugar anómalo en que se encuentran o por otras causas análogas [...] (CNCiv., Sala H., 29/5/1997, “S., J.B. c/ Espejar S.A.”, LA LEY, 1999-C, 722, p.3).14

Específicamente para los supuestos de daños derivados de una actividad riesgosa, el art. 1758 in fine pone el deber de responder en cabeza de "quien la realiza, se sirve u obtiene provecho de ella, por sí o por terceros, excepto lo dispuesto por la legislación especial”.

En la interpretación tradicional de esta norma diversos autores distinguen la existencia de hasta dos posibles sujetos pasivos del deber de responder: 1) la persona que realiza la actividad riesgosa; 2) la persona que se sirve u obtiene provecho de la actividad riesgosa; en lo que podría denominarse como "teoría bipartita de sujetos pasivos". ${ }^{15}$

\footnotetext{
${ }^{13} \mathrm{El}$ art. $1757 \mathrm{CCCN}$ establece que las actividades pueden ser riesgosas o peligrosas por su naturaleza, por los medios empleados o por las circunstancias de su realización.

${ }^{14}$ En los términos señalados por la norma, se puede calificar a la producción forestal como una actividad riesgosa por las circunstancias de su realización. En efecto, hemos citado anteriormente sus consecuencias nocivas cuando viene asociada al uso intensivo de agroquímicos o las plantaciones se efectúan con alto grado de densidad por hectárea o en grandes extensiones. ${ }^{15}$ Estas lecturas concuerdan con las realizadas respecto del art. 1113 C.Civ. antecedente del art. 1758 CCCN), en las que generalmente se señalaban los mismos posibles legitimados pasivos.
} 
En palabras de Pizarro:

“Conforme lo dispone el art. 1758, responde quien realiza, se sirve u obtiene provecho de la actividad riesgosa o peligrosa, por sí o por terceros, excepto lo dispuesto por legislación especial. Realiza la actividad riesgosa quien de manera autónoma lleva a cabo o ejecuta la actividad riesgosa, por sí o por terceros. Se sirve u obtiene provecho de la actividad riesgosa quien satisface a través de la misma un interés patrimonial o extrapatrimonial. A menudo quien realiza la actividad riesgosa es quien se sirve u obtiene un provecho de ella. Pero puede ello no ser así y aparecer ambas calidades disociadas. En tal caso, ambos responden" (2015, p.4).

En la misma línea, aunque poniendo el énfasis en la inmutabilidad de la regla pos-reforma, Compagnucci de Caso sostiene que:

“...en el supuesto del "riesgo de actividad", los responsables son el operador o quien la realiza, y el que se sirve y obtiene provecho de dicha actividad. Creo que no hay incorporación de noveles responsables, sino que se mantiene la característica de ser el "guardián" el que debe asumir la carga de estar obligado, ya que será consecuencia de la guarda material, jurídica o de provecho la que dará causa suficiente a ello" (2014, p.186).

Para Galdós (2012), quien también adhiere a la teoría bipartita, junto a la figura del realizador de la actividad riesgosa, se sitúa como obligado la persona que se sirve u obtiene provecho generalmente económico de dicha actividad, y siempre y cuando éste último tenga facultades de organización o de control sobre las tareas peligrosas.

Sin embargo, también es posible afirmar que el art. 1758 in fine comprende en realidad la descripción de tres supuestos de responsabilidad, y no solamente de dos - como señalan los autores mencionados-. Además de quien realiza la actividad, pueden ubicarse como personas distintas quien se sirve de la misma, por un lado, y quien obtiene provecho de ella, por otro.

Esto importa distinguir y admitir la separabilidad de dos conceptos o situaciones posibles: la de servirse de una actividad y la de sacar provecho de una actividad.

La expresión "servirse de" es empleada en diversos artículos del código, con la aclaración de que siempre aparece vinculada a una cosa (y no a una actividad, como sucede en la hipótesis bajo análisis). En los arts. 1367 (depósito irregular), 1536 y 1538 (obligaciones del comodatario), 2180 (derechos del titular del fundo sirviente), 2018 y 2020 (medianería), "servirse" importa valerse de la cosa según el uso que es propio de ella, y requiere tener el control o la ocupación de la cosa. Aquí, servirse de una actividad riesgosa equivaldría a obtener la finalidad material directa de la actividad, hacerse con su efecto inmediato. Por ejemplo, se sirve 
de la aplicación de un producto plaguicida quien lleve adelante la explotación agrícola cuyas plantaciones crecerán en mejores condiciones luego de la aplicación de dicha sustancia (en comparación a los resultados que obtendría si no se hubiera utilizado el producto).

Por otro lado, la noción de lograr, sacar u obtener "provecho" es utilizada en numerosos artículos a lo largo del nuevo cuerpo normativo. En la mayoría de las veces, aparece asociada a la consecución de un beneficio económico en sentido estricto (véanse los arts. 493, monto de las recompensas en la liquidación de la comunidad de bienes; 1035, saneamiento; 1324 inc. g, obligaciones del mandatario; 1794 y 1799 inc. a, enriquecimiento sin causa; 1936, responsabilidad por destrucción de la cosa). En otros casos - los menos- el beneficio no se concibe como una ventaja únicamente económica sino que bien puede ser de índole general (1224, extinción de la locación; 1934 inc. f, definición de mejora suntuaria; 2381, atribución preferencial en la partición).

Naturalmente, quien ejecuta la actividad riesgosa espera hacerse con los efectos inmediatos o materiales de dicha actividad (es decir, "servirse" de ella), así como también aspira a obtener el provecho económico derivado de la misma. Siguiendo el ejemplo dado, quien aplica el plaguicida tiene la expectativa de que su explotación tenga un rendimiento mayor (o sea quiere "servirse" de la actividad), y a la vez la misma persona espera hacerse con las ventajas económicas derivadas de esas consecuencias materiales (es decir, desea "obtener provecho" de la actividad desplegada).

Sin embargo, puede también perfectamente ocurrir que una persona se vea beneficiada económicamente por la actividad riesgosa ("obtenga provecho") sin haber sido la destinataria de los efectos materiales inmediatos de dicha actividad, es decir sin que se haya servido de ella.

Esto sucede, por ejemplo, cuando se constituye derecho real de superficie sobre un fundo con la finalidad principal de efectuar allí una explotación agrícola o forestal, y se estipula en oportunidad de suscribir el contrato constitutivo que el precio a pagar al propietario se determinará en función directa del rendimiento de la producción llevada a cabo por el superficiario. En este esquema de contratación, el propietario obtiene mayores ingresos cuando el superficiario incrementa el rendimiento de la explotación. Si este incremento se produce como consecuencia del ejercicio de una actividad riesgosa, entonces es correcto sostener que el superficiario es quien se sirve de la actividad aplicada sobre la cosa (toda vez que su producción se ve materialmente favorecida en cantidad y/o calidad) y es también quien maximiza o incrementa sus ganancias (saca provecho económico de las diferencias materiales en la producción). Al mismo tiempo, sería válido afirmar que el propietario, aunque no se sirva de la actividad riesgosa desplegada por el superficiario, también obtiene provecho de la misma vía incremento del precio que percibe por el derecho de superficie otorgado (sería un beneficiario no servido).

El análisis podría extenderse a todos los casos en que se desdobla o se separa titularidad y explotación u ocupación efectiva de la cosa mediante contratos en los que el precio a percibir se fija en relación al rendimiento obtenido en la explotación, y se generen mayores niveles de rendimiento como consecuencia de la ejecución de actividades riesgosas durante el proceso productivo. Quedan comprendidos en la problemática, por ende, la constitución de derechos de personales, como los 
derivados de locaciones, entre otros, siempre que no tuvieran regulación especial en contrario. ${ }^{16}$

En resumen, frente a la posición tradicional o lectura clásica de legitimación pasiva (teoría bipartita) en materia de daños derivados de actividades riesgosas (art. 1758 in fine), surge entonces, con base en los fundamentos expuestos, la cuestión de la posible extensión de la responsabilidad al "propietario aprovechador" en su condición de beneficiario no servido (postura tripartita).

En este escenario, el trabajo se propone indagar a continuación si a la luz de los nuevos parámetros de interpretación consagrados por el CCCN se debería formular una relectura de la citada norma imputativa de responsabilidad civil, dando cabida a este tercer supuesto de legitimación pasiva por daños ambientales indirectos derivados de actividades riesgosas, o, por el contrario, resulta más razonable mantenerse dentro de la posición bipartita.

\section{PAUTAS DE INTERPRETACIÓN Y DETERMINACIÓN DE SUJETOS RESPONSABLES}

Respecto a la actividad interpretativa el CCCN establece en su art. 2 la necesidad de que en la interpretación del derecho se conjugue el texto expreso de la norma, con su finalidad, las leyes análogas, los tratados sobre derechos humanos y los principios y valores jurídicos, "de modo coherente con todo el ordenamiento".

En palabras de la doctrina,

“... el Código Civil y Comercial [...] pretende ser el factor de integración del conjunto de los microsistemas del derecho privado. Dicho de otro modo, las fuentes dialogan: las leyes especiales, los microsistemas, no existen en el aislamiento, en el vacío, sin interrelación alguna; al contrario, sin perjuicio de sus reglas específicas, pueden acudir al CCyC como instrumento de integración al sistema (Kemelmajer, 2015, p. XV y XVI).

El artículo citado consagra el mandato de perseguir una integración armónica del sistema jurídico, teniendo en consideración en todo momento a las normas de jerarquía superior y las leyes especiales. Esta búsqueda exige repensar permanentemente los derechos y obligaciones de los sujetos, los que irán cambiando inexorablemente a medida que se introduzcan innovaciones al ordenamiento vía incorporación de tratados de derechos humanos, leyes especiales

\footnotetext{
${ }_{16}$ Como sucede en la Ley de Arrendamientos Rurales y Aparcería № 13.246, que en su art. 42 prohíbe convenir la fijación del
} precio en función de los frutos obtenidos por el arrendatario (Ilamado contrato canadiense). 
o, simplemente, por medio de la reinterpretación de estas fuentes, y a medida que las nuevas realidades tornen obsoletas las viejas interpretaciones. ${ }^{17}$

En el marco de este nuevo paradigma proponemos analizar si la interpretación tripartita del art. 1758 CCCN se ciñe convenientemente a los términos de la normativa especial, y sobre todo, si es superadora de la versión tradicional (bipartita) en el sentido de que se integra y complementa más adecuadamente con el ordenamiento como un todo.

En esta dirección, la Ley General del Ambiente (LGA), que es la ley especial en la materia, enumera al "sistema de control sobre el desarrollo de actividades antrópicas" como uno de los instrumentos de política ambiental (art. 8 inc. 3). Por tanto, las regulaciones que imponen deberes de tutela ambiental y asignan responsabilidades en caso de producción de daños forman parte del sistema de control sobre actividades antrópicas y deben ser reputadas como instrumentos de política ambiental. Se sigue de ello que resulta acertado calificar al art. $1758 \mathrm{CCCN}$ in fine como una norma que integra y que debe funcionar en sintonía con la política ambiental nacional.

La misma LGA en su art. 4 establece que la interpretación de toda norma a través de la cual se ejecute la política ambiental queda sujeta al cumplimiento de una serie de principios, entre los que se encuentra el principio de prevención que es tomado directamente de la Constitución Nacional.

Explica la doctrina ambientalista que:

“...la Constitución Nacional, consagra en el artículo 41, el derecho al ambiente sano, equilibrado, apto para el desarrollo humano [...], y el desarrollo sustentable. Pero también, establece el "deber de preservarlo", lo que se condice con los principios de política ambiental, de prevención y precaución, contenidos en el artículo $4^{\circ}$ y $5^{\circ}$ de la Ley 25675 General del Ambiente. Dichos principios, obligan al operador jurídico - el juez, la autoridad competente o de aplicación de la normativa ambiental-, metodológicamente, a priorizar el análisis, en la etapa previa al daño (PRE-DAÑO), operando sobre las causas y las fuentes de los problemas ambientales, tratando de impedir la consumación del daño ambiental (Cafferatta, 2014, p.10).

Este precepto constitucional, plasmado en el principio de prevención del art. 4 de la LGA, debe necesariamente ser tenido en cuenta al interpretar normativa del CCCN que posea inje-

\footnotetext{
17 "El Código Civil y Comercial de la Nación inaugura su Título Preliminar refiriendo a los "casos" que este Código rige. Un "caso", como tal, no se entiende como un suceso histórico en su dimensión puramente fáctica; por el contrario, para el Derecho se trata, esencialmente, de un acontecimiento problemático que plantea la cuestión - muchas veces ardua- acerca de cómo responder a él en términos jurídicos. Las dificultades en la resolución de algunos de estos "casos" (hard cases) en una sociedad cada vez más compleja exigen generar continuas reconstrucciones interpretativas del ordenamiento vigente." (Kemelmajer, Fernández y Herrera, 2015, p.1, el destacado es propio).
} 
rencia clara o que directamente forme parte de la política ambiental, y cabe resaltar que esta pauta se complementa armónicamente y se refuerza con la nueva función preventiva del sistema de responsabilidad general adoptado por el CCCN en el art. 1710 y siguientes. ${ }^{18}$

Reflexionando, entonces, sobre la manera de interpretar el conjunto de posibles sujetos responsables señalados por el art. 1758 in fine que mejor se adecue al principio constitucional de prevención del daño ambiental y a la función preventiva del nuevo sistema de responsabilidad del CCCN, parece razonable postular que la versión tripartita es superadora de la bipartita.

La aseveración se fundamenta en que la incorporación del propietario "aprovechador". ${ }^{19}$ Como responsable por daños ambientales indirectos ocasionados por el superficiario y el usuario genera incentivos para que una persona adicional (el propietario) lleve adelante medidas de control de la actividad riesgosa, aumentando así las posibilidades de prevención de daños ambientales. ${ }^{20}$

Asimismo, desde el punto de vista axiológico, la solución propuesta puede considerarse valiosa. La versión bipartita permite que el propietario, en las circunstancias ya descriptas, se apropie o capte parte de las mayores ganancias, sin que pueda imputársele responsabilidad alguna en caso de que la actividad riesgosa del usufructuario o superficiario genere daños ambientales indirectos. La interpretación tripartita evita esta situación injusta, cargando también sobre el propietario los eventuales impactos ambientales negativos de las actividades riesgosas. Bajo este último esquema, el propietario debe interesarse no sólo en el cuidado de sus propios bienes, sino también en la conducta del usufructuario o superficiario y en que el uso que éste hace sobre la cosa entregada para su explotación no dañe a terceros.

La interpretación sugerida importa la utilización de un factor de atribución objetivo de daños ${ }^{21}$, en el que no son eximentes la autorización administrativa para la realización de la actividad, ni el cumplimiento de las técnicas de prevención. ${ }^{22}$

\footnotetext{
18 “El ingreso del principio de prevención al Código Civil y Comercial, fortalece la postura de defensa del ambiente. Aunque hace tiempo se sabe en la doctrina que el Derecho de Daños incluye además de la resarcitoria o indemnizatoria, una función preventiva y disuasiva, es valioso que expresamente se establezca esta regla de funcionalidad del instituto de la responsabilidad civil, en todas sus variantes". (Cafferatta, 2014, p. 13). En sentido concordante puede verse Lorenzetti (2013).

${ }^{19}$ Aquel propietario que obtiene un beneficio económico mayor o extraordinario como consecuencia de rendimientos productivos incrementados mediante actividades riesgosas llevadas a cabo por el superficiario o usufructuario.

${ }^{20}$ Así como las chances de reparación o recomposición en caso de que el daño se verifique, al agregar un patrimonio adicional sobre el cual perseguir el cobro de las indemnizaciones debidas.

${ }^{21}$ ARTICULO 1722 CCCN.- Factor objetivo. El factor de atribución es objetivo cuando la culpa del agente es irrelevante a los efectos de atribuir responsabilidad. En tales casos, el responsable se libera demostrando la causa ajena, excepto disposición legal en contrario.

${ }^{22}$ ARTICULO 1757 CCCN.- Hecho de las cosas y actividades riesgosas. Toda persona responde por el daño causado por el riesgo o vicio de las cosas, o de las actividades que sean riesgosas o peligrosas por su naturaleza, por los medios empleados o por las circunstancias de su realización. La responsabilidad es objetiva. No son eximentes la autorización administrativa para el uso de la cosa o la realización de la actividad, ni el cumplimiento de las técnicas de prevención.
} 


\section{CONCLUSIONES}

En resumen, bajo los nuevos parámetros de responsabilidad ambiental por daños indirectos, el propietario puede ser considerado responsable por daños ocasionados por el usufructuario o superficiario que ejecuta actividades riesgosas, cuando aquel se apropie de parte de la mayor rentabilidad económica generada por dicha actividad. Esta es la interpretación normativa que mejor se condice con los preceptos constitucionales, con las disposiciones de la ley especial aplicable y con la función preventiva del nuevo sistema general de responsabilidad civil.

\section{REFERENCIAS BIBLIOGRÁFICAS}

Abreut, L. e Iturbide, G. (sin fecha). Reflexiones sobre el nuevo derecho real de superficie forestal, La Ley Online; sin página. Cita Online: AR/DOC/328/2005.

Alterini, J. (2003). Superficie Forestal. Revista del Notariado, (873), pp. 121. Cita Online: AR/DOC/5793/2011.

Cafferatta, N. (2009). Los daños al ambiente y su reparación. Daño Ambiental Revista de Derecho de Daños, 3.

Cafferatta, N.( 17/11/2014). Derecho ambiental en el Código Civil y Comercial de la Nación, La Ley, Sup. Esp. Nuevo Código Civil y Comercial 2014 (Noviembre), p. 10.

Carrere, R. (2004). Respuestas a diez mentiras. $1^{\text {a }}$ Reimpresión. Montevideo, Uruguay: Movimiento Mundial por los Bosques Tropicales.

Compagnucci de Caso, R. (2014). Comentario al artículo 1758. Bueres, A. (Dir.). Código Civil y Comercial de la Nación analizado, comparado y concordado. 1a ed. Buenos Aires, Argentina: Hammurabi. Vol. 2, p.186-197.

Cossari, N. y Luverá, M. (01/01/2002). Derecho real de superficie forestal (Breve comentario a la ley 25.509), La Ley Litoral, p. 685. Cita Online: AR/DOC/10303/2001.

Di Paola, M. (2010). El Daño Ambiental. Sabsay, D. (Dir). Constitución de la Nación Argentina y normas complementarias. Análisis doctrinal y jurisprudencial. Buenos Aires, Argentina: Hammurabi. Tomo 2, p.218-231. 


\begin{tabular}{c}
\hline HARAVÍ ELOÍSA RUIZ - GUILLERMO GAPEL REDCOZUB \\
$>148$ \\
REINTERPRETANDO LA RESPONSABILIDAD DEL PROPIETARIO ANTE DAÑO AMBIENTAL INDIRECTO... \\
Págs. $131-149$ \\
\hline
\end{tabular}

FAO. (2002). Bibliografía anotada sobre los efectos ambientales, sociales y económicos de los eucaliptos. (Working Paper FP/17S). Recuperado de http://www.fao.org/docrep/005/ y7605s/y7605soo.htm

Galdós, J. (2012). Riesgo creado y actividad riesgosa en el Proyecto 2012 de Código Civil y Comercial de la Nación. Revista Derecho de Daños, La Ley, (3), p. 345.

Galdós, J. (23/03/2016). Responsabilidad por actividades riesgosas y peligrosas en el nuevo Código, La Ley, pp. 1-5.

Gómez de la Lastra, M. (25/01/2013). La superficie forestal, el Proyecto de Código Civil y la ley de tierras rurales, La Ley, p. 676. Cita Online: AR/DOC/5477/2012.

Kemelmajer, A. (2015). Prólogo. Caramelo, G.; Picasso, S. y Herrera, M. (Dirs.). Código Civil y Comercial de la Nación comentado. 1a ed. Ciudad Autónoma de Buenos Aires: Infojus. Tomo I, pp. XV - XIX.

Kemelmajer, A., Fernández, S. y Herrera, M. (18/08/15). Bases para una relectura de la restricción a la capacidad civil en el nuevo Código, La Ley, p.1.

Kiper, C. (2015). Comentario al artículo 20121 en Ricardo Lorenzetti (Dir). Código Civil y Comercial de la Nación Comentado. $1^{0}$ ed. Santa Fe, Argentina: Rubinzal Culzoni. Tomo 9, pp.729-731.

López Alfonsín, M. (2012). Derecho Ambiental, Buenos Aires, Argentina: Astrea.

Lorenzetti, P. (2013). Funciones de la responsabilidad civil y daño ambiental en el Proyecto de Código Civil y Comercial de la Nación de 2012. Revista Responsabilidad Civil y Seguros, (8), p. 5, Cita Online: AR/DOC/2574/2013.

Mariani de Vidal, M. y Abella, A. (23/02/2016). Derecho real de superficie en el Código Civil y Comercial, La Ley, p. 1. Cita Online: AR/DOC/507/2016.

Overbeek W., Kröger M. y Gerber J. (2012). Una panorámica de las plantaciones industriales de árboles en los países del Sur. Conflictos, tendencias y luchas de resistencia Recuperado de http://wrm.org.uy/oldsite/publicaciones/ejolt.html 
Pizarro, R. (12/o8/2015). Responsabilidad civil por actividades riesgosas o peligrosas en el nuevo Código, La Ley, pp. 1-5.

Pizarro, R. (2015). Tratado de Responsabilidad Objetiva. Tomo II. Buenos Aires, Argentina: Thomson Reuters La Ley.

\section{CURRICULUM VITAE}

\section{Haraví Eloísa Ruiz}

Abogada, Facultad de Derecho y Ciencias Sociales, Universidad Nacional del Nordeste (UNNE). Especialista en Docencia Universitaria, Facultad de Humanidades (UNNE). Especialista en Teoría y Técnica del Proceso Judicial, Facultad de Derecho (UNNE). Miembro de las Cátedras de Derecho Agrario y Ambiental, Facultad de Derecho (UNNE) y de Instituciones del Derecho Privado II, Facultad de Ciencias Económicas (UNNE).

haraviruiz@gmail.com

\section{Guillermo Gapel Redcozub}

Abogado, Facultad de Derecho, Universidad Nacional del Nordeste (UNNE). Licenciado en Economía, Facultad de Ciencias Económicas (UNNE). Especialista en Docencia Universitaria, Facultad de Humanidades (UNNE). Master of Laws (Harvard Law School, EEUU). Profesor Titular Regular de Derechos Reales, Facultad de Derecho (UNNE).

guillermogapel@gmail.com 